\title{
Uncertainty, Intelligence, and National Security Decision Making
}

\author{
David R. Mandel ${ }^{\mathrm{a} *}$ and Daniel Irwin ${ }^{\mathrm{b}}$
}

${ }^{a}$ Intelligence, Influence and Collaboration Section, Defence Research and Development Canada, 1133 Sheppard Avenue West, Toronto, ON M3K 3C9, Canada; ${ }^{b}$ Department of National Defence, Toronto, Canada

*corresponding author: drmandel66@gmail.com,orcid.org/0000-0003-1036-2286

David R. Mandel is a senior Defence Scientist with Defence Research and Development Canada and Adjunct Professor of Psychology at York University. He publishes widely in peer-reviewed journals and has co-authored or co-edited five books on reasoning, judgment, and decisionmaking. Mandel was Chairman of NATO's SAS-114 Research Technical Group on Assessment and Communication of Uncertainty in Intelligence to Support Decision Making (SAS-114), which received the NATO SAS Panel Excellence Award in 2020. Author can be contacted at drmande166@gmail.com.

Daniel Irwin holds a MS in Applied Intelligence from Mercyhurst University and works for Canada's Department of National Defence, conducting research on intelligence analysis and uncertainty communication. His work has been published in Intelligence and National Security and Risk Analysis. In 2020, Irwin was awarded the NATO SAS Panel Excellence Award for his contributions to NATO SAS-114. Author can be contacted at dan.irwin@drdc-rddc.gc.ca. 
Intelligence analysis and national security decision-making are pervaded by uncertainty. The most consequential decisions that leaders make, such as whether to go to war, are mired in uncertainties not only reflecting what is unknown but also what is unknowable, such as the intentions of others who may not have made up their own minds. ${ }^{1}$ Those uncertainties not only make decisions about how to resolve international conflicts more difficult, they change the odds of going to war. Powerful countries seldom wage war to conquer weaker ones but rather to prevent them from developing breakout technologies that could threaten them in the long run. ${ }^{2}$ Such decisions are inevitably made under uncertainty, and the deeper and more vexing the uncertainties are, the more likely war is to follow as a conflict resolution strategy.

The centrality of uncertainty to decision-making at the highest policy levels regarding whether to wage war underscores the primacy of accurately assessing and clearly communicating uncertainties to decision-makers. This is a central analytic function of intelligence. While intelligence organizations are empowered by incredible collections technologies, it is the analyst who transforms the raw data into assessments for decision-makers. As Sherman Kent, a founder of modern US intelligence analysis aptly noted, most substantive intelligence is not fact but expert judgment made under uncertainty. ${ }^{3}$ Not only does the analyst have to reason through uncertainties to arrive at sound and hopefully accurate judgments, but the uncertainties must also be clearly communicated to policymakers who must decide how to act upon the intelligence. Thomas Fingar, former US Deputy Director of National Intelligence, described the role of intelligence as centrally focusing on reducing uncertainty for the decision-maker. ${ }^{4}$ While analysts cannot always reduce uncertainty, they should be able to accurately estimate and clearly communicate key uncertainties for decision-makers. ${ }^{5}$ 
Given the importance of uncertainty in intelligence, one might expect the intelligence community to draw upon relevant science aimed at effectively handling uncertainty, much as it has done to fuel its vast collections capabilities. Yet remarkably, methods for uncertainty communication are far from having been optimized, even though the problem of uncertainty communication has resurfaced in connection with significant intelligence failures. For instance, governmental post-mortems of the Iraq Weapons of Mass Destruction (WMD) misestimate that provided a pretext for the 2003 Iraq Invasion concluded that an important contributing factor was failure to communicate to key leaders the uncertainties inherent in the estimates. ${ }^{6}$ What makes this longstanding situation so perplexing is that the theoretical advances needed to improve uncertainty handling have existed for decades.

\section{INTELLIGENCE COMMUNITY APPROACHES TO UNCERTAINTY Kent's Early Brush with Ambiguity}

Current intelligence methods for uncertainty communication trace back to what Kent described as his early brush with ambiguity. ${ }^{7}$ Following a 1951 National Intelligence Estimate (NIE) on the former Yugoslavia, Kent was queried by the State Department Policy Planning Staff chairman about the meaning of serious possibility, an uncertainty term used to describe the likelihood of a Soviet or satellite attack on Yugoslavia that year. Kent interpreted the term to mean about a $65 \%$ chance in favor of an attack, which surprised the chairman who thought it meant a substantially lower chance. Kent was also surprised when he found that analysts he queried gave estimates for the term ranging from a $20 \%$ to $80 \%$ chance. This prompted Kent and his colleague, Max Foster, to develop a standard for communicating uncertainty (see Figure 1). The standard provided "words of estimative probability" — namely, linguistic probabilities - along with numeric range equivalents, which are strikingly similar to those promulgated in 
recent years. However, Kent found that many analysts were adamantly opposed to the initiative. Kent pejoratively described these analysts as "poets", contrasting them with "mathematicians" who were open to such reform. Kent's standard, like other similar attempts over the years, failed to take root and he blamed this on the poets. ${ }^{8}$

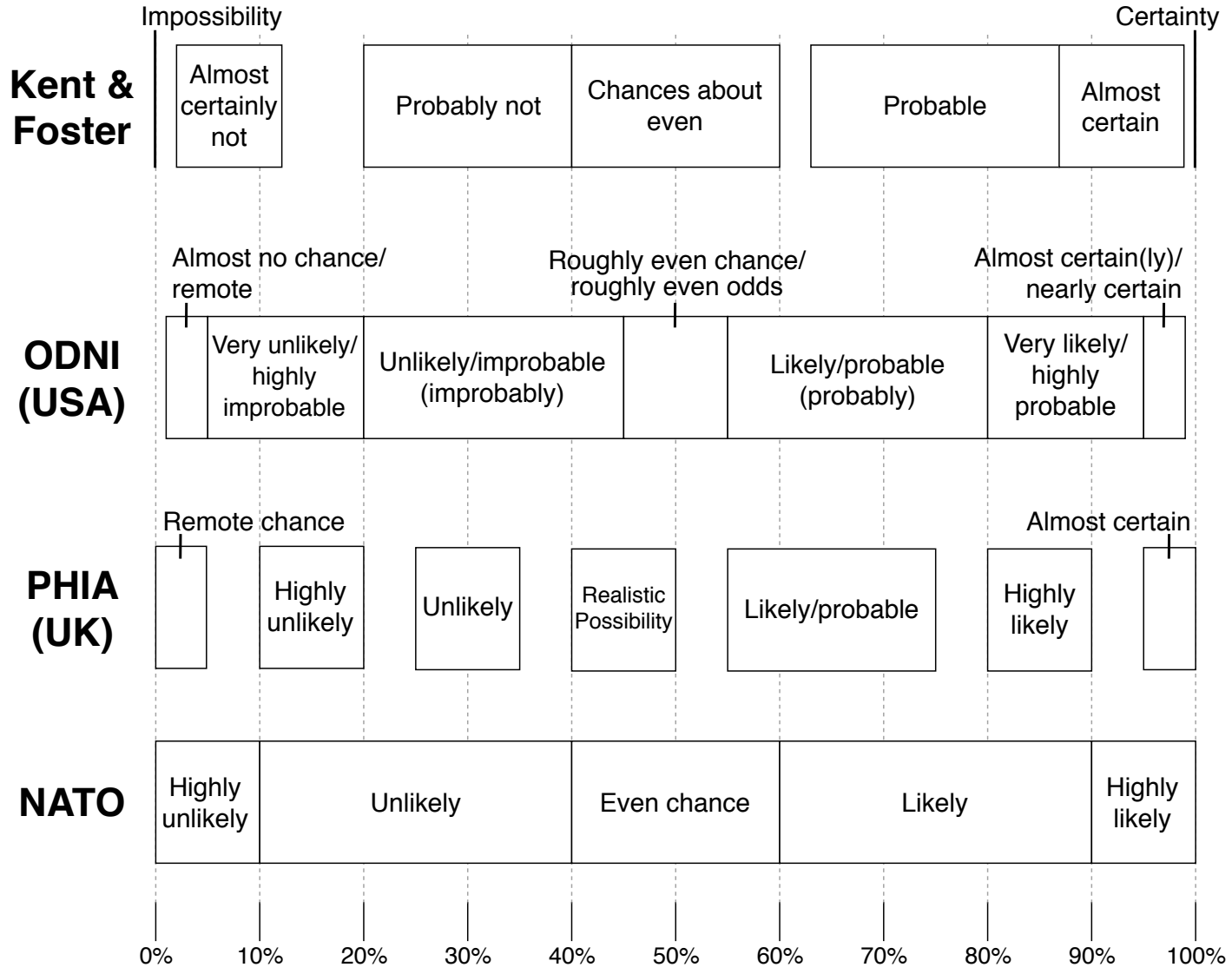

Figure 1. Lexicons developed for communicating probability in intelligence. ${ }^{9}$

\section{Contemporary Standards}

Most intelligence organizations today use some variant of the Kent-Foster approach.

That is, they rely on curated sets of linguistic probability terms presented as ordered scales. Previously, some of these scales did not use numeric probability equivalencies. ${ }^{10}$ However, nowadays, most standards assign numeric ranges to stipulate the meaning of each linguistic probability term. Figure 1 contrasts the Kent-Foster standard with those currently mandated by the US Office of the Director of National Intelligence (ODNI), 
the UK Professional Head of Intelligence Analysis (PHIA), and NATO. ${ }^{11}$

Efforts to transform the vagueness of natural language into something clearer reflect a noble goal, but the curated-list approach is flawed in practice and in principle. For example, flaws in practice include the fact that each standard uses a common approach, yet each differs sufficiently to undermine interoperability among key collaborative partners; e.g., an even chance issued by NATO could mean unlikely, roughly even chance, or likely in the US system. Current standards also prevent analysts from communicating probabilities less than $1 \%$ or greater than $99 \%$. This pre-empts analysts from distinguishing "one in a hundred" from "one in a million." In the US standard, "one in a hundred" is the smallest communicable probability, while in the NATO and UK standards, "one in a million" would be indistinguishable from "one in ten." Orders of magnitude should matter to experts because orders of magnitude matter in everyday life. A threat that has a $10 \%$ chance of occurring may call for a different response than if it had a one-in-a-million chance of occurring instead. While such problems are ostensibly correctable, in practice, they have proven resistant to correction. $^{12}$

\section{KEY PROBLEMS WITH THE CONTEMPORARY APPROACH}

\section{Linguistic Probabilities All But Guarantee Miscommunication}

Even if the ostensibly correctable problems were fixed, there are fundamental problems with the current approach to uncertainty handling that challenge its soundness, in principle. The most significant issues include the fact that linguistic probability phrases are inherently vague and context dependent, infused with "between-the-lines" meaning. A voluminous scientific literature reveals that interpretations of linguistic probabilities vary widely between individuals (i.e., different individuals assign different numeric equivalents to the same phrase), with considerable overlap among the numeric ranges 
assigned to certain terms. ${ }^{13}$ Individuals often assign different numeric probabilities to the same phrase on different occasions. ${ }^{14}$ Translations of linguistic probabilities to numeric equivalents vary depending on contextual factors including content domain, outcome valence, outcome severity, base-rate frequency, magnitude, and presentation format. ${ }^{15}$ Even individuals trained to associate a set of linguistic expressions with specific numeric equivalents interpret the same expressions differently in novel contexts. ${ }^{16}$ Interpretations also vary with personal characteristics of interpreters, such as numeracy, language, personal attitudes, and locus of control. ${ }^{17}$ Of particular relevance to international organizations like NATO, native English speakers interpret linguistic probabilities differently than non-native English speakers. ${ }^{18}$ Significant inter-cultural variation also exists. $^{19}$

Probability phrases also serve pragmatic face-management functions that can undermine epistemic communication goals. ${ }^{20}$ Speakers may choose expressions to preserve a receiver's public image by exaggerating positive-outcome probabilities or minimizing negative-outcome probabilities. ${ }^{21}$ Speakers also use linguistic probabilities to minimize blame, consistent with the metaphor of people as "intuitive politicians" strategically minding their reputations. ${ }^{22}$ Such strategies include overstating negativeoutcome probabilities (i.e., "better safe than sorry") or minimizing positive-outcome probabilities (i.e., “don’t get your hopes up”).

Linguistic probabilities also convey "directionality," a linguistic feature related to but distinct from probability. ${ }^{23}$ Directionally-positive expressions (e.g., "some possibility") convey optimism and suggest focal events will occur, while directionallynegative expressions (e.g., "quite uncertain”) convey pessimism and suggest nonoccurrence. These implicit suggestions can influence decision-making outside of the 
decision-maker's awareness. ${ }^{24}$ In the intelligence context, they undermine the requirement for policy neutrality. ${ }^{25}$

Intelligence organizations have naively assumed that they can quash the unruliness of linguistic probabilities simply by stating their intended meaning. ${ }^{26}$ Yet ample research shows that when people have direct access to a translation table, a large proportion still interprets linguistic expressions inconsistently with the prescribed meanings. ${ }^{27}$ These findings have been shown in the domain of climate science and, more recently, intelligence production. ${ }^{28}$ Noting the abysmal rates of shared understanding when probability lexicons are provided, researchers have recommended that numeric ranges be reported alongside linguistic probabilities in assessments. ${ }^{29}$ However, this approach has yielded only modest improvements in shared understanding. ${ }^{30}$ It also risks miscommunication because readers could easily interpret such intervals as issue-specific credible intervals rather than clarifications of the meaning of the associated terms.

The intelligence community's recognized need to clarify linguistic probabilities with numeric ranges calls their use into question. Decision-makers want useful (i.e., timely, relevant, and accurate) information to support their decisions; they don't wish to be reminded repeatedly what probability terms should mean to them when consuming intelligence. Any standard that encourages analysts to express anything other than their best probability estimate for the event being judged is suboptimal. In place of linguistic probabilities, analysts should be encouraged to assign numeric probability intervals, which can be as precise as is appropriate under the circumstances. For instance, an analyst could provide a credible interval of $65-85 \%$ that a given event will occur (or that a given claim is true). This signifies clearly that the probability is believed to lie between $65 \%$ and $85 \%$. Presented with such an interval, one can easily derive a best 
estimate from the midpoint (i.e., $[65+85] / 2)$ and an associated margin of error (i.e., [85 $-65] / 2$ ), in this case yielding an equivalent point estimate of $75 \%$ plus or minus $10 \% .^{31}$

This mode of uncertainty communication would address most of the issues hitherto identified. Numeric probability intervals would help clarify the analyst's assessment and attenuate the vagueness intrinsic in linguistic uncertainty expressions. ${ }^{32}$ This would diminish the impact of inter-standard inconsistencies and linguistic or cultural barriers, thereby promoting interoperability. Of course, numeric probabilities are not perfectly transparent. People vary in their assumptions about distributions underlying numeric intervals. ${ }^{33}$ Numeric quantifiers can also be ambiguous and contextdependent. ${ }^{34}$ Nevertheless, compared to linguistic probabilities, numeric probabilities are far less susceptible to context effects and elastic redefinition. ${ }^{35}$ Unlike linguistic probabilities, numeric probabilities have a transparent ordering that users agree upon. Numeric probabilities also enable analysts to convey extreme probabilities with as much precision as warranted. They do not force a collapse of the base-10 logarithmic scale to a single value such as "remote chance," as current standards do.

\section{Confusion over Confidence}

Another shortcoming of the intelligence community's approach to uncertainty handling is its treatment of analytic confidence. Current standards require analysts to convey their confidence using coarse ordinal ratings that usually have low, medium, and high

levels. ${ }^{36}$ Perhaps worse, analysts are usually instructed to assess probability and confidence as if they were independent constructs. Such standards fail to explain that confidence is a second-order judgment of uncertainty capturing one's subjective margin of error in a probabilistic estimate. ${ }^{37}$ That is, the less confident analysts are in their estimates, the wider their credible intervals should be. An analyst who believes the probability of an event lies between $50 \%$ and $90 \%$ (i.e., $70 \%$ plus or minus $20 \%$ ) is less 
confident than an analyst who believes that the probability lies between $65 \%$ and $75 \%$ (i.e., $70 \%$ plus or minus $5 \%$ ). The analyst providing the wider margin of error plays it safer than the analyst providing the narrower interval, presumably because the former is less confident than the latter. If this weren't true, the former analyst would be imposing an unfair cost on the end-user since increasing imprecision reduces informativeness. ${ }^{38}$

Current standards send mixed messages about confidence. When analysts select a probability phrase, the numeric range given in a lexicon could be misinterpreted as a confidence interval. Since decision-makers are presumably more interested in the substantive issues covered in an intelligence report than how the meanings of vague words are resolved, they might misinterpret the ranges. Advice to analysts to treat confidence ratings as independent of probability assessments also can yield nonsensical estimates at both ends of the probability scale. For instance, if a judgment of highly likely, interpreted as "more than $90 \%$ " in the NATO standard, is made with low confidence, the only way to translate the confidence level into variation of the stipulated range $(90-100 \%)$ is to go downwards. This is almost certain to confuse decision-makers.

Historical evidence shows that intelligence practitioners misunderstand the probability-confidence dissociation. In the 2007 NIE on Iranian nuclear capabilities, probabilistic expressions (e.g., probably, unlikely) are said to "reflect the [Intelligence] Community's estimates of the likelihood of developments or events." ${ }^{39}$ Meanwhile, confidence levels indicate the extent to which "assessments and estimates are supported by information that varies in scope, quality and sourcing. ${ }^{, 40}$ Despite this guidance being prominently featured in the product, Friedman and Zeckhauser observed 19 instances in the declassified key judgments section where "confidence" is used to express probability, rather than qualify it. ${ }^{41}$ At no point in the key judgments are expressions of 
probability and confidence used to jointly characterize uncertainty as officially intended. $^{42}$

Decision-makers also seem to find the current distinction confusing and would benefit from a unified quantitative expression of probability and confidence. For instance, during a 2013 US congressional hearing, Rep. Doug Lamborn inadvertently disclosed a line from a Defense Intelligence Agency (DIA) assessment stating, "DIA assesses with moderate confidence the North [Korea] currently has nuclear weapons capable of delivery by ballistic missiles." 43 According to DIA standards from the time, moderate confidence meant: "partially corroborated information from good sources, several assumptions, and/or a mixture of strong and weak inferences. ${ }^{, 44}$ Despite this guidance, several hearing members dismissed the assessment outright, apparently assuming that judgments issued with less than high confidence could be disregarded. ${ }^{45}$

Nor do quantitative assessments preclude clear prose explaining the bases for judgment. Explanation is vital to intelligence since without it, a decision-maker would not know how the particular assessment was reached. Numeric assessments and clear explanations should work together to yield effective intelligence. Offering a useful template for intelligence narratives about analytic confidence, Friedman and Zeckhauser propose three central components: 1) the reliability of evidence supporting an assessment; 2) the range of reasonable opinion surrounding an assessment; and 3) the extent to which analysts believe an assessment could change given additional information. ${ }^{46}$ Forecasters reliably discriminated between these components and decision-makers used them reliably ${ }^{47}$ Therefore, analysts might benefit from training that exposes them to frameworks for thinking systematically about these components of confidence. On the job, analysts could be incentivized to provide rationales outlining how these considerations shaped the width of their credible intervals. This approach 
should improve accountability, facilitating post-mortem analyses that gauge the degree to which analysts were miscalibrated. It could also help consumers decide whether to act on intelligence or to task additional collection and analytic capabilities. ${ }^{48}$

\section{UNCERTAINTY COMMUNICATION REFORM}

\section{Why It's Needed}

Intelligence producers and consumers are periodically required to combine multiple probabilistic estimates. ${ }^{49}$ For instance, averaging is relevant when consumers must integrate assessments from multiple advisors. As a case study of President Barack Obama's decision-making during the search for Osama bin Laden highlighted, Obama was frustrated by the disparate set of estimates he received. ${ }^{50}$ Such frustration might have been alleviated had the estimates been conveyed as an average with a margin of error. The ability to multiply probability estimates can play a vital role in estimating the conjunctive probability of threat scenarios that require multiple necessary conditions to be met for the threat to manifest. For example, analysts might assess the probability of a terrorist attack based on the product of the individual probabilities of adversarial intent, adversarial capability, and one's own vulnerability to attack. Methods, such as interval analysis, permit arithmetic operations with numeric intervals to be easily computed. ${ }^{51}$ In contrast, fuzzy-logic methods enabling arithmetic operations on linguistic probabilities require considerable knowledge about how the sender interprets these probabilities. ${ }^{52}$ This approach is infeasible and has not been applied in intelligence practice. Nor are people adept at averaging or multiplying linguistic probabilities. In recent experiments, people were more accurate and coherent when averaging and multiplying probabilities if they were presented numerically rather than linguistically. ${ }^{53}$ 
Numeric probabilities also have advanced applications. They support Bayesian networks, through which analysts can coherently pool and revise judgments. ${ }^{54}$ Numeric probabilities would also allow intelligence organizations to exploit accuracy-boosting post-analytic methods that can be applied to judgments from one or more analysts. Unlike structured analytic techniques that attempt to debias the analyst prior to and during assessment, post-analytic methods improve the quality of assessments after they are made. ${ }^{55}$ For example, numeric estimates can be mathematically recalibrated to correct for observable biases such as underconfidence or overconfidence. ${ }^{56}$ They can also be recalibrated so that they are coherent, respecting axioms of probability calculus, a process that also improves accuracy. ${ }^{57}$ Further research shows how combining postanalytic methods can boost intelligence analysts' accuracy, whereas much-touted intelligence methods like Analysis of Competing Hypotheses paled in comparative effectiveness. $^{58}$

Numeric probabilities also enable systematic monitoring of assessment accuracy based on well-established quantitative scoring rules. ${ }^{59}$ These measures provide an audit trail for assessments and discourage play-it-safe tactics by incentivizing accuracy. ${ }^{60}$ Accuracy monitoring empowers intelligence organizations to identify areas for improvement and permits empirical validation of corrective policies. For instance, in an analysis of the accuracy of six years of classified intelligence forecasts, Mandel and Barnes observed superb accuracy coupled with substantial underconfidence (i.e., analysts assigned more uncertainty than required given their high degree of accuracy), which was correctable through a recalibration procedure. ${ }^{61}$ Such monitor-and-adjust procedures support active organizational learning. In contrast, intelligence communities currently lack the means of objectively, systematically, and proactively measuring the quality of analytic judgment. ${ }^{62}$ They instead rely on process-based accountability 
procedures that direct analysts to "be accurate" or to use structured analytic techniques, which research suggests may be unhelpful if not outright detrimental. ${ }^{63}$ In short, using numeric probabilities would not only improve uncertainty communication, it would improve the quality of intelligence analysis and intelligence oversight.

\section{Obstacles}

Given the shortcomings of the current approach to uncertainty communication and the clear benefits of using numeric probabilities, why hasn't effective reform happened? In part, organizational inertia reflects the fact that most intelligence consumers have limited time in office, finite political capital, and crowded agendas. ${ }^{64}$ Efforts to tackle intelligence-community esoterica deplete resources and promise little in the way of electoral payoff. ${ }^{65}$ High turnover of elected officials also ensures short collective memory; practitioners can count on mistakes being forgotten without having to modify their tradecraft. ${ }^{66}$ Even when commissions are expressly tasked with intelligence reform, they often lack the requisite knowledge base, resulting in superficial solutions. ${ }^{67}$ The introduction of embedded translation guides that gloss over the fundamental problems of vague and leading language while introducing new avenues for error is a case in point.

Similar factors impede reform driven internally by intelligence practitioners. ${ }^{68}$ As a former intelligence director, Alan Barnes required the use of numeric probabilities among his analysts. ${ }^{69}$ While Barnes found that skeptical analysts quickly adapted to their use, his reforms were abandoned after his retirement, and applications of his approach in other parts of the Canadian intelligence community have been partial, modified in questionable ways, and generally short-lived. ${ }^{70}$ James Marchio described a similar experience at DIA, where internal support for numeric probabilities rose in the 
1970s (coinciding with increased demand from consumers) but then lost momentum following turnover of agency leadership. ${ }^{71}$

While leadership turnover and resource constraints impede meaningful reform in most large bureaucracies, these factors are compounded, in the US at least, by the fragmented and adversarial nature of the federal system. ${ }^{72}$ Examining 14 major reviews of the intelligence community conducted between 1947 and 2005, Warner and McDonald found that only four produced noteworthy organizational change. ${ }^{73}$ Substantive reform was generally contingent on sustained support from the White House and/or Congress; concurrent studies endorsed by present and future leaders of the intelligence community; and a war or crisis serving as a catalyst. ${ }^{74}$ Even when these conditions were met, reforms were modest compared to what was originally proposed, reflecting the abundance of veto players and the depth of partisan division. ${ }^{75}$

Beyond these institutional barriers, intelligence producers and consumers alike may view it in their best interests to sacrifice epistemic quality in intelligence to better serve other pragmatic goals. ${ }^{76}$ For consumers, linguistic probabilities provide wiggle room to interpret intelligence estimates in ways that align with their policy preconceptions and preferences - and if things go wrong, they have the intelligence community to blame for its lack of clarity. ${ }^{77}$ Historically, intelligence consumers have exploited imprecision to justify decisions and deflect blame when they produced negative outcomes. ${ }^{78}$ For example, in building a case for the invasion of Iraq, US decision-makers made conclusive claims about Saddam Hussein's WMD programs based on vague intelligence estimates, particularly those presented in the 2002 NIE Iraq's Continuing Programs for Weapons of Mass Destruction. ${ }^{79}$ After the Iraq Survey Group failed to locate any WMD, decision-makers scapegoated the intelligence community by reframing its fuzzy conclusions as overconfident. ${ }^{80}$ When the 
intelligence community accurately characterizes uncertainty and forces consumers to consider alternative outcomes, it undermines their ability to oversell policies. ${ }^{81}$ The imperatives of leadership survival may clash with the intelligence community's oftcited mission to "speak truth to power," and can create perverse incentives for vague communication.

Self-interested intelligence producers may also believe that they benefit from the interpretive flexibility afforded by linguistic probabilities. ${ }^{82}$ By hedging their estimates, analysts can effectively avoid falsification; an estimate that a focal event could happen cannot be found definitively "wrong." ${ }^{, 83}$ Many of the forecasts that Mandel and Barnes excluded from their quantitative analyses of accuracy were removed for this reason. ${ }^{84}$ This self-protective strategy is not unique to the intelligence domain, nor is it irrational, given the tendency of some consumers to shoot the messenger when estimates are carefully qualified or misaligned with their policy preferences. ${ }^{85}$ Several studies challenge conventional wisdom that fuzzy estimates shield analysts from blame. Dieckmann and colleagues observed that, when dealing with higher probability events, decision-makers rated judgments qualified with numeric uncertainty ranges as more useful and credible than those without. ${ }^{86}$ Other studies find that erroneous judgments expose analysts to less criticism when communicated numerically than linguistically, although the relation between communication format and credibility is moderated by other factors. ${ }^{87}$ In sum, using linguistic probabilities to deflect blame is a tactic that often backfires.

Intelligence directors may similarly resist reforms that expose their units to outcome-based accountability metrics. ${ }^{88}$ Generally speaking, intelligence organizations are wary of any mechanism that facilitates objective evaluation, especially if it exposes inferior performance relative to rival agencies. ${ }^{89}$ This anxiety is pronounced in the US 
intelligence community, where intelligence functions are split between 17 agencies, resulting in zero-sum "turf wars" over resources and jurisdiction. ${ }^{90}$ Charged with ensuring analytic quality across the community, ODNI maintains a parochial focus on process, such as promoting compliance with prescribed analytic methods and issuing goal directives without specifying viable means of achieving them, rather than outcome accountability, which would involve tracking judgment accuracy. ${ }^{91}$ This may reflect the fact that assessing accuracy can bureaucratically threaten intelligence agencies and sow discord between them. ${ }^{92}$

In the intelligence community and beyond, the imperative to deflect blame drives organizations to embed defensive tactics (e.g., the use of vague linguistic probabilities) into their standard operating procedures. ${ }^{93}$ Similar forces contribute to institutional isomorphism, the tendency of bureaucracies towards homogenization in terms of structure and output. ${ }^{94}$ Isomorphism is pronounced in organizational fields characterized by ambiguous goals and uncertain operating environments-two defining features of intelligence. ${ }^{95}$ According to this explanation, linguistic probabilities are not the prevalent mode of uncertainty communication across the intelligence community due to their effectiveness but because no agency wants to draw scrutiny by deviating from established protocols.

\section{Correcting Correctable Ignorance}

Organization inertia also reflects widespread but correctable ignorance regarding the shortcomings of existing methods, the risks that they pose to decision quality, and the viability of alternative modes of uncertainty communication. People generally have trouble acquiring a sound understanding of probabilistic concepts-experts (including those routinely dealing with uncertain estimates) aren't exempt from statistical illiteracy. ${ }^{96}$ Most objections raised by such experts to using numeric probabilities belie 
popular misconceptions about probability and their bearing on decision quality. ${ }^{97}$

A common dissent is the "false precision" argument. Since Kent first proposed pairing linguistic expressions with numeric equivalents, critics have insisted that communicating judgments with numbers exaggerates precision and wrongly implies scientific rigor. ${ }^{98}$ Former US Deputy Secretary of State James Steinberg conveyed this view when he cautioned, "I am somewhat skeptical of what I believe is a false sense of correctness implied by assigning numerical probabilities to individual events."99 Variants of the false precision argument also arise in intelligence studies, and in other fields resistant to numeric probability expressions, such as medicine. ${ }^{100}$ Proponents of such arguments seem unaware (or unwilling to admit) that uncertainty may be quantified with varying degrees of precision.

An offshoot of the false precision argument is the claim that numbers are inappropriate because not all analytic judgments are forecasts. This is a strawman argument. No one claims otherwise, although Mandel and Barnes found that threequarters of judgments made in strategic intelligence reports were in fact forecasts, and Kent identified forecasts as the most important type of estimate the intelligence community could deliver to policymakers. ${ }^{101}$ Numeric probability intervals are equally applicable whether referring to past, present, or future states of the world under conditions of epistemic uncertainty; there is no situation in which an analyst can coherently provide a linguistic probability but not a numeric one. ${ }^{102}$

That said, there are reasonable bases for practitioners' discomfort with numeric probabilities. Assigning numeric probabilities requires more mental effort than assigning linguistic probabilities. People regularly use linguistic probabilities to signal intent. It is not only harder to determine that one has an $80 \%$ probability or even a 60 $80 \%$ chance of going to a meeting than to judge it likely, it may also feel unnecessary to 
expend the additional effort. The speaker may intend likely to mean little more than "I think I will go, but I am not sure.” When this level of precision suffices, there are arguments for using linguistic probabilities. ${ }^{103}$ Certain situations in intelligence production may fall into this category, but most don't. It is implausible that the cases where greater precision, granularity, and clarity are warranted are so few in number and collectively so inconsequential as to merit the continuation of the current approach.

Compounding the intelligence community's misunderstanding of probabilities is the widespread belief that intelligence consumers prefer linguistic probabilities, or alternatively, that they are unable to make effective use of numeric estimates. ${ }^{104}$ While declassified intelligence products reveal a strong institutional preference for communicating probabilities linguistically, the claim that this reflects widespread consumer preferences relies heavily on anecdotal evidence. ${ }^{105}$ Studies show that people generally prefer to communicate probabilistic information linguistically, but that they also prefer to receive it numerically. ${ }^{106}$ These preferences are exhibited across a range of expert judgment communities, but are particularly pronounced when judgments are based on unreliable or incomplete information, as is characteristic of intelligence analysis. $^{107}$

Experiments conducted in the context of intelligence forecasting indicate that decision-makers are not averse to numeric probability ranges and can reliably detect subtle differences between numeric estimates, even when devoting limited effort to the task. ${ }^{108}$ Concerns that numeric expressions render consumers overconfident and excessively risk seeking also lack empirical support. In one study, national security officials receiving numeric probability assessments were less prone to support risky actions and more amenable to gathering additional information prior to decisionmaking. ${ }^{109}$ 


\section{CONCLUSION}

Extensive research has shown that linguistic probabilities are inherently vague, they convey implicit recommendations, and they serve other pragmatic functions that can mar the integrity of policy-neutral assessments aimed at supporting sound decisionmaking. The mandated dissociation of probability and confidence assessments also undermines communication fidelity and fosters an incoherent understanding of the relation between these distinct, but related concepts. A quantitative approach to uncertainty communication that uses numeric probability intervals complemented with written rationales would be more informative and less vulnerable to misinterpretation (accidental or deliberate). Numeric probabilities would also enable intelligence agencies to objectively monitor their forecasting accuracy and leverage a suite of accuracyboosting techniques, with downstream benefits for decision-making quality.

Despite the strong empirical case for using numeric probabilities, persistent barriers to intelligence reform remain. Political and bureaucratic realities constrain prospective reformers and foster a cynical, risk-averse culture. The status quo also persists due to ignorance about uncertainty, which manifests itself in a variety of erroneous claims about uncertainty that go unchallenged inside the intelligence community's cultural echo chamber. The intelligence community now operates in a post-Moneyball, post-FiveThirtyEight world. It faces growing competition from alternative information brokers that are exploiting forecasting science to make sophisticated predictions. ${ }^{110}$ If the intelligence community hopes to maintain its analytic relevance this century, it must provide unique and actionable insights. A clear sign of added value is intelligence that is as precise, granular, accurate, and informative as the evidence warrants. The proposal to use numeric probability ranges supplemented with clear explanatory text would support those objectives. 
Funding information: This work was supported by the Canadian Safety and Security Program under Project \#2018-TI-2394 (Decision Science for Superior Intelligence Production).

\section{REFERENCES}

${ }^{1}$ Sherman Kent, "Words of Estimative Probability," in Sherman Kent and the Board of

National Estimates: Collected Essays, ed. Donald P. Steury (Washington, DC: Center for

${ }^{2}$ Alexandre Debs and Nuno P. Monteiro, "Known Unknowns: Power Shifts, Uncertainty, and

War," International Organization, Vol.68, No.1 (2014): pp.1-31.

${ }^{3}$ Kent, "Words."

${ }^{4}$ Thomas Fingar, Reducing Uncertainty: Intelligence Analysis and National Security (Stanford:

Stanford Security Studies, 2011).

${ }^{5}$ Jeffrey A. Friedman and Richard Zeckhauser. “Assessing Uncertainty in Intelligence,"

Intelligence and National Security, Vol.27, No.6 (2012): pp.824-47.

${ }^{6}$ See "The Decision to Go to War in Iraq" (Cm 6062, UK House of Commons Foreign Affairs

Committee, London: The Stationery Office, 2003), at

https://assets.publishing.service.gov.uk/government/uploads/system/uploads /attachment data/file/272087/6062.pdf; "Iraqi Weapons of Mass Destruction -

Intelligence and Assessments" (Cm 5972, UK House of Commons Intelligence and

Security Committee, London: The Stationery Office, 2003), at

https://assets.publishing.service.gov.uk/government/uploads/system/uploads/attachment_d ata/file/272079/5972.pdf; "Report on the U.S. Intelligence Community’s Prewar Intelligence Assessments on Iraq" $\left(108^{\text {th }}\right.$ Congress, US Congressional Select Committee on Intelligence, Washington, DC: Government Printing House, 2004), at https://fas.org/irp/congress/2004 rpt/ssci iraq.pdf; Lord Butler of Brockwell, "Review of Intelligence on Weapons of Mass Destruction" (HC 898, UK Committee of Privy Counsellors, London: The Stationery Office, 2004), at https://fas.org/irp/world/uk/butler071404.pdf; Sir John Chilcot, "The Report of the Iraq Inquiry: Executive Summary" (HC 264, UK Committee of Privy Counsellors, London, The Stationery Office, 2016), at https://assets.publishing.service.gov.uk/government/uploads/system/uploads/attachment_d ata/file/535407/The Report_of the_Iraq_Inquiry__Executive_Summary.pdf.

${ }^{7}$ Kent, "Words."

${ }^{8}$ Kristan J. Wheaton, "The Revolution Begins on Page Five: The Changing Nature of NIEs," International Journal of Intelligence and CounterIntelligence, Vol.25, No.2 (2012): pp.330-49; James Marchio, “'If the Weatherman Can...': The Intelligence Community's 
Struggle to Express Analytic Uncertainty in the 1970s," Studies in Intelligence, Vol.58, No.4 (2014): pp.31-42; Alan Barnes, "Making Intelligence Analysis More Intelligent: Using Numeric Probabilities," Intelligence and National Security, Vol.31, No.3 (2016): pp.327-44.

${ }^{9}$ Figure created by the authors based the following standards: Kent, "Words"; "Intelligence Community Directive 203" (Office of the Director of National Intelligence, Washington, DC: ODNI, 2015), at https://fas.org/irp/dni/icd/icd-203.pdf; "Intelligence Collection, Analysis and Dissemination Policy Framework" (UK Ministry of Justice and HM Prison and Probation Service, London: UK Ministry of Justice and HMPPS, 2019), pp.9-10, at https://assets.publishing.service.gov.uk/government/uploads/system/uploads/attachment dat a/file/843803/intelligence-collection-management-dissemination-pf-31-oct-2019.pdf; "Allied Joint Doctrine for Intelligence Procedures,” AJP-2.1, edition B, version 1 (North Atlantic Treaty Organization, Brussels: NATO Standardization Office, 2016).

${ }^{10}$ Daniel Irwin and David R. Mandel, "Variants of Vague Verbiage: Intelligence Community Methods for Communicating Probability," in Assessment and Communication of Uncertainty in Intelligence to Support Decision Making: Final Report of Research Task Group SAS-114, ed. David R. Mandel (Brussels: NATO Science and Technology Organization, 2020), pp.317-46.

11 "Intelligence Community Directive 203"; "Intelligence Collection”; “Allied Joint Doctrine”; see also comparison of US and UK standards in Mandeep K. Dhami and David R. Mandel, "Words or Numbers? Communicating Probability in Intelligence Analysis," American Psychologist (forthcoming).

${ }^{12}$ For an overview of 'correctable' shortcomings, see Irwin and Mandel, "Variants"; Daniel Irwin and David R. Mandel, "How Intelligence Organizations Communicate Confidence (Unclearly)," in Assessment and Communication of Uncertainty in Intelligence to Support Decision Making: Final Report of Research Task Group SAS-114, ed. David R. Mandel (Brussels: NATO Science and Technology Organization, 2020), pp.347-66.

${ }^{13}$ David L. Wark, "The Definition of Some Estimative Expressions," Studies in Intelligence, Vol.8, No.4 (1964): pp.67-80; Edgar M. Johnson, Numerical Encoding of Qualitative Expressions of Uncertainty (Arlington: US Army Research Institute for Behavioral and Social Sciences, 1973); Ruth Beyth-Marom, "How Probable is Probable? A Numerical Translation of Verbal Probability Expressions," Journal of Forecasting, Vol.1, No.3 (1982): pp.257-69; David V. Budescu and Thomas S. Wallsten, “Consistency in Interpretation of Probabilistic Phrases," Organizational Behavior and Human Decision Processes, Vol.36, No.3 (1985): pp.391-405; Robert T. Reagan, Frederick Mosteller, and 
Cleo Youtz, "Quantitative Meanings of Verbal Probability Expressions," Journal of Applied Psychology, Vol.74, No.3 (1989): pp.433-42; Karl H. Teigen and Wibecke Brun, "Yes, but it is Uncertain: Direction and Communicative Intention of Verbal Probabilistic Terms," Acta Psychologica, Vol.88, No.3 (1995): pp.233-58.

${ }^{14}$ Budescu and Wallsten, "Consistency"; David V. Budescu and Thomas S. Wallsten, "Dyadic

Decisions with Numerical and Verbal Probabilities," Organizational Behavior and Human Decision Processes, Vol.46, No.2 (1990): pp.240-63.

${ }^{15}$ For content domain, see Beyth-Marom, "How Probable"; Wibecke Brun and Karl H. Teigen, "Verbal Probabilities: Ambiguous, Context Dependent, or Both?" Organizational Behavior and Human Decision Processes, Vol.41, No.3 (1988): pp.390-404; Barbara A. Mellers, Joshua D. Baker, Eva Chen, David R. Mandel, and Philip E. Tetlock, "How Generalizable is Good Judgment? A Multi-task, Multi-benchmark Study," Judgment and Decision Making, Vol.12, No.4 (2017): pp.369-81; for outcome valence, see Brent L. Cohen and Thomas S. Wallsten, "The Effect of Constant Outcome Value on Judgments and Decision Making Given Linguistic Probabilities," Journal of Behavioral Decision Making, Vol.5, No.1 (1992): pp.53-72; David R. Mandel, “Communicating Numeric Quantities in Context: Implications for Decision Science and Rationality Claims," Frontiers in Psychology, Vol.6 (2015): p.537; for outcome severity, see Jon F. Merz, Marek J. Druzdzel, and Dennis J. Mazur, "Verbal Expressions of Probability in Informed Consent Litigation,” Medical Decision Making, Vol.11, No.4 (1991): pp.273-81; Adam J.

L. Harris and Adam Corner, "Communicating Environmental Risks: Clarifying the Severity Effect in Interpretations of Verbal Probability Expressions," Journal of Experimental Psychology: Learning, Memory, and Cognition, Vol.37, No.6 (2011): pp.1571-78; for base-rate frequency, see Thomas S. Wallsten, Samuel Fillenbaum, and James A. Cox, "Base Rate Effects on the Interpretations of Probability and Frequency Expressions," Journal of Memory and Language, Vol.25, No.5 (1986): pp.571-87; for magnitude, see Weber, Elke U., and Denis J. Hilton, "Contextual Effects in the Interpretations of Probability Words: Perceived Base Rate and Severity of Events," Journal of Experimental Psychology: Human Perception and Performance, Vol.16, No.4 (1990): pp.781-89; for presentation format, see Robert M. Hamm, "Selection of Verbal Probabilities: A Solution for Some Problems of Verbal Probability Expression," Organizational Behavior and Human Decision Processes, Vol.48, No.2 (1991): pp.193223; Anne Bergenstrom and Lorraine Sherr, "The Effect of Order of Presentation of Verbal Probability Expressions on Numerical Estimates in a Medical Context," Psychology, Health \& Medicine, Vol.8, No.4 (2003): pp.391-98. 
${ }^{16}$ Wallsten, Fillenbaum, and Cox, "Base Rate."

${ }^{17}$ For numeracy, see David V. Budescu, Han-Hui Por, and Stephen B. Broomell, "Effective Communication of Uncertainty in the IPCC Reports," Climatic Change, Vol.113, No.2 (2012): pp.181-200; for language, see Zachary Brooks, "Bilingual Decision Making: Verbal Probability, Ethics, and Cognition,” (PhD diss., University of Arizona, 2016); for personal attitudes, see M. David Piercey, "Motivated Reasoning and Verbal vs. Numerical Probability Assessment: Evidence from an Accounting Context," Organizational Behavior and Human Decision Processes, Vol.108, No.2 (2009): pp.330-41; Budescu, Por, and Broomell, "Effective Communication"; for locus of control, see W. Ross Hartsough, "Assignment of Subjective Probabilities to Verbal Probability Phrases as a Function of Locus of Control and Set Conditions," The Journal of Psychology, Vol.95, No.1 (1977): pp.87-97.

${ }^{18}$ Brooks, "Bilingual Decision Making."

${ }^{19}$ Timothy Doupnik and Edson Luiz Riccio, "The Influence of Conservatism and Secrecy on the Interpretation of Verbal Probability Expressions in the Anglo and Latin Cultural Areas," The International Journal of Accounting, Vol.41, No.3 (2006): pp.237-61; Adam J. L. Harris, Adam Corner, Juemin Xu, and Xiufang Du, "Lost in Translation? Interpretations of the Probability Phrases Used by the Intergovernmental Panel on Climate Change in China and the UK," Climatic Change, Vol.121 (2013): pp.415-25; Ning Du, Kevin Stevens, and Anton I. Shigaev, "Cross-cultural Differences in Interpreting IAS 37 Probability Phrases,” International Journal of Financial Research, Vol.7, No.1 (2015): pp.1-8.

${ }^{20}$ Penelope Brown and Stephen C. Levinson, Politeness: Some Universals in Language Usage. (New York: Cambridge University Press, 1987); Jean-François Bonnefon and Gaëlle Villejoubert, "Communicating Likelihood and Managing Face: Can We Say it is Probable When We Know it to be Certain?" in Proceedings of the 27th annual conference of the Cognitive Science Society, eds. Bruno G. Bara, Lawrence Barsalou, and Monica Bucciarelli (Mahwah, NJ: Erlbaum, 2005), pp.316-21; Jean-François Bonnefon and Gaëlle Villejoubert, "Tactful or Doubtful? Expectations of Politeness Explain the Severity Bias in the Interpretation of Probability Phrases," Psychological Science, Vol.17, No.9 (2006): pp.747-51.

${ }^{21}$ Marie Juanchich and Miroslav Sirota, "Do People Really Say it is "Likely" When They Believe it is Only 'Possible'? Effect of Politeness on Risk Communication,” The Quarterly Journal of Experimental Psychology, Vol.66, No.7 (2013): pp.1268-75; Thomas 
Holtgraves and Audrey Perdew, "Politeness and the Communication of Uncertainty," Cognition, Vol.154 (2016): pp.1-10.

${ }^{22}$ Marie Juanchich, Miroslav Sirota, and Christina Lea Butler, "The Perceived Functions of Linguistic Risk Quantifiers and their Effect on Risk, Negativity Perception and Decision Making," Organizational Behavior and Human Decision Processes, Vol.118, No.1 (2012): pp.72-81; Miroslav Sirota and Marie Juanchich, “A Direct and Comprehensive Test of Two Postulates of Politeness Theory Applied to Uncertainty Communication," Judgment and Decision Making, Vol.10, No.3 (2015): pp.232-40; Philip E. Tetlock, "Social Functionalist Frameworks for Judgment and Choice: Intuitive Politicians, Theologians, and Prosecutors," Psychological Review, Vol.109, No.3 (2002): pp.451-71; David R. Mandel and Philip E. Tetlock, "Debunking the Myth of Value-Neutral Virginity: Toward Truth in Scientific Advertising," Frontiers in Psychology, Vol.7 (2016): p.451.

${ }^{23}$ Brun and Teigen, "Verbal Probabilities"; Teigen and Wibecke Brun, "Yes, but it is Uncertain"; Teigen and Brun, "The Directionality of Verbal Probability Expressions:

Effects on Decisions, Predictions, and Probabilistic Reasoning," Organizational Behavior and Human Decision Processes, Vol.80, No.2 (1999): pp.155-90; Teigen and Brun, "Verbal Probabilities: A Question of Frame?" Journal of Behavioral Decision Making, Vol.16, No.1 (2003): pp.53-72; Shlomi Sher and Craig R. M. McKenzie, "Information Leakage from Logically Equivalent Frames," Cognition, Vol.101 (2006): pp.467-94.

${ }^{24}$ Teigen and Brun, "Directionality"; Karl H. Teigen and Wibecke Brun, "Ambiguous Probabilities: When Does $p=0.3$ Reflect a Possibility, and When Does it Express a Doubt?" Journal of Behavioral Decision Making, Vol.13, No.3 (2000): pp.345-62; Hidehito Honda and Kimihiko Yamagishi, "Directional Verbal Probabilities: Inconsistencies Between Preferential Judgments and Numerical Meanings," Experimental Psychology, Vol.53, No.3 (2006): pp.161-70; Hidehito Honda and Kimihiko Yamagishi, "Perceived Certainty Based on Verbal Probability Phrases: Effect of Directionality and its Dependence on Method," Japanese Psychological Research, Vol.51, No.4 (2009): pp.266-73; Christophe Schmeltzer and Denis J. Hilton, “To Do or Not to Do? A Cognitive Consistency Model for Drawing Conclusions from Conditional Instructions and Advice," Thinking \& Reasoning, Vol.20, No.1 (2014): pp.16-50.

${ }^{25}$ Robert N. Collins and David R. Mandel, "Cultivating Credibility with Probability Words and Numbers," Judgment and Decision Making, Vol.14, No.6 (2019): pp,683-95.

${ }^{26}$ For a recent example, see Annex B in "Background to 'Assessing Russian Activities and Intentions in Recent US Elections': The Analytic Process and Cyber Incident Attribution 
(Office of the Director of National Intelligence, 2017), at https://www.dni.gov/files/documents/ICA_2017_01.pdf.

${ }^{27}$ David V. Budescu, Stephen B. Broomell, and Han-Hui Por, "Improving Communication of Uncertainty in the Reports of the Intergovernmental Panel on Climate Change," Psychological Science, Vol.20, No.3 (2009): pp.299-308; Budescu, Por, and Broomell, "Effective Communication”; David V. Budescu, Han-Hui Por, Stephen B. Broomell, and Michael Smithson, "The Interpretation of IPCC Probabilistic Statements Around the World,” Nature Climate Change, Vol.4 (2014): pp.508-12; Bonnie C. Wintle, Hannah Fraser, Ben C. Wills, Ann E. Nicholson, and Fiona Fidler, "Verbal Probabilities: Very Likely to be Somewhat More Confusing than Numbers," PLoS One, Vol.14, No.4 (2019): e0213522.

${ }^{28}$ Ibid.

${ }^{29}$ Ibid.

${ }^{30}$ Ibid.

${ }^{31}$ Ramon E. Moore, R. Baker Kearfott, and Michael J. Cloud., Introduction to Interval Analysis (Philadelphia: Society for Industrial and Applied Mathematics, 2009): pp.1-9; Note that one cannot derive an interval from a single point estimate unless the error bounds are also known.

${ }^{32}$ Barnes, "Making Intelligence."

${ }^{33}$ Nathan F. Dieckmann, Ellen Peters, and Robin Gregory, "At Home on the Range? Lay Interpretations of Numerical Uncertainty Ranges,” Risk Analysis, Vol.35, No.7 (2015): pp.1281-95.

${ }^{34}$ Mandel, "Communicating Numeric Quantities."

${ }^{35}$ Piercey, "Motivated Reasoning"; Miroslav Sirota and Marie Juanchich, "To What Extent Do Politeness Expectations Shape Risk Perception? Even Numerical Probabilities Are under Their Spell!" Acta Psychologica, Vol.141, No.3 (2012), pp.391-99.

${ }^{36}$ Irwin and Mandel, "Intelligence Organizations."

${ }^{37}$ Nathan F. Dieckmann, Robert Mauro, and Paul Slovic, “The Effects of Presenting Imprecise Probabilities in Intelligence Forecasts," Risk Analysis, Vol.30, No.6 (2010): pp.987-1001.

${ }^{38}$ Ilan Yaniv and Dean P. Foster, "Graininess of Judgment Under Uncertainty: An Accuracyinformativeness Trade-off," Journal of Experimental Psychology: General, Vol.124, No.4 (1995): pp.424-32.

39 "National Intelligence Estimate - Iran: Nuclear Intentions and Capabilities" (Office of the Director of National Intelligence, Washington, DC: ODNI, 2007), at 
https://www.dni.gov/files/documents/Newsroom/Reports\%20and\%20Pubs/20071203 rele ase.pdf, p.5.

${ }^{40}$ Ibid.

${ }^{41}$ Friedman and Zeckhauser, "Assessing Uncertainty.”

${ }^{42}$ Ibid.

${ }^{43}$ Mark Schneider, "The North Korean Nuclear Threat to the U.S." Comparative Strategy, Vol.33, No.2 (2014): p.107.

44 "What We Mean When We Say” (Defence Intelligence Agency, Washington, DC: DIA, 2010).

${ }^{45}$ Mark M. Lowenthal, Intelligence: From Secrets to Policy, $7^{\text {th }}$ ed. (Washington, DC: CQ Press, 2016), pp.193-94.

${ }^{46}$ Jeffrey Friedman and Richard Zeckhauser, "Analytic Confidence and Political Decision Making: Theoretical Principles and Experimental Evidence From National Security Professionals,” Political Psychology, Vol.39, No.5 (2018): pp.1069-87.

${ }^{47}$ Ibid.

${ }^{48}$ Ibid.; Dieckmann, Mauro, and Slovic, "Effects"; see comparable recommendations regarding information evaluation in Daniel Irwin and David R. Mandel, "Improving Information Evaluation for Intelligence Production,” Intelligence and National Security, Vol.34, No.4 (2019): pp.503-25.

${ }^{49}$ Thomas S. Wallsten and Adele Diederich, "Understanding Pooled Subjective Probability Estimates," Mathematical Social Sciences, Vol.41, No.1 (2001): pp.1-18; Dhami and David R. Mandel, "Words or Numbers?"

${ }^{50}$ Jeffrey A. Friedman and Richard Zeckhauser, "Handling and Mishandling Estimative Probability: Likelihood, Confidence, and the Search for Bin Laden," Intelligence and National Security, Vol.30, No.1 (2015): pp.77-99.

${ }^{51}$ Moore, Kearfott, and Cloud, Interval Analysis, pp.11-14.

${ }^{52}$ Lotfi A. Zadeh, "The Concept of a Linguistic Variable and its Application to Approximate Reasoning-III," Information Sciences, Vol.9, No.1 (1975): pp.43-80; Didier Dubois and Henri Prade, “Operations on Fuzzy Numbers," International Journal of Systems Science, Vol.9, No.6 (1977): pp.613-26.

${ }^{53}$ David R. Mandel, Mandeep K. Dhami, Serena Tran, and Daniel Irwin, "Arithmetic Computation with Probability Words and Numbers," (manuscript submitted for publication). 
${ }^{54}$ Christopher W. Karvetski, Kenneth C. Olson, Donald T. Gantz, and Glenn A. Cross, "Structuring and Analyzing Competing Hypotheses with Bayesian Networks for Intelligence Analysis," EURO Journal on Decision Processes, Vol.1 (2013): pp.205-31.

${ }^{55}$ David R. Mandel and Philip E. Tetlock, "Correcting Judgment Correctives in National Security Intelligence," Frontiers in Psychology, Vol.9 (2018): p.2640; David R. Mandel, "The Occasional Maverick of Analytic Tradecraft," Intelligence and National Security, Vol.35, No.3 (2020): pp.438-43.

${ }^{56}$ Jonathan Baron, Barbara A. Mellers, Philip E. Tetlock, Eric Stone, and Lyle H. Ungar, “Two Reasons to Make Aggregated Probability Forecasts More Extreme," Decision Analysis, Vol.11, No.2 (2014): pp.133-45; Brandon M. Turner, Mark Steyvers, Edgar C. Merkle, David V. Budescu, and Thomas S. Wallsten, "Forecast Aggregation via Recalibration," Mach Learn, Vol.95 (2014): pp.261-89; Mandel and Barnes, "Accuracy."

${ }^{57}$ Christopher W. Karvetski, Kenneth C. Olson, David R. Mandel, and Charles R. Twardy, "Probabilistic Coherence Weighting for Optimizing Expert Forecasts," Decision Analysis, Vol.10, No.4 (2013): pp.305-26; Yuyu Fan, David V. Budescu, David R. Mandel, and Mark Himmelstein, "Improving Accuracy by Coherence Weighting of Direct and Ratio Probability Judgments," Decision Analysis, Vol.16, No.3 (2019): pp.197-217.

${ }^{58}$ David R. Mandel, Christopher W. Karvetski, and Mandeep K. Dhami, "Boosting Intelligence Analysts' Judgment Accuracy: What Works, What Fails?" Judgment and Decision Making, Vol.13, No.6 (2018): pp.607-21; Christopher W. Karvetski, David R. Mandel, and Daniel Irwin, "Improving Probability Judgment in Intelligence Analysis: From Structured Analysis to Statistical Aggregation," Risk Analysis, Vol.40, No.5 (2020): pp.1040-57.

${ }^{59}$ Mandel and Barnes, “Accuracy"; Mandel and Barnes, "Geopolitical Forecasting”; Barbara A. Mellers, Lyle Ungar, Jonathan Baron, Jaime Ramos, Burcu Gurcay, Katrina Fincher, Sydney E. Scott, Don Moore, Pavel Atanasov, Samuel A. Swift, Terry Murray, Eric Stone, and Philip E. Tetlock, "Psychological Strategies for Winning a Geopolitical Forecasting Tournament," Psychological Science, Vol.25, No.5 (2014): pp.1106-15; Welton Chang and Philip E. Tetlock, "Rethinking the Training of Intelligence Analysts," Intelligence and National Security, Vol.31, No.6 (2016): pp.903-20.

${ }^{60}$ Michael Schrage, “What Percent is 'Slam Dunk'?” The Washington Post, February 20, 2005, at https://www.washingtonpost.com/archive/opinions/2005/02/20/what-percent-is-slamdunk/812c1bc6-2f25-4783-a2da-c1256a6d4031/.

${ }^{61}$ Mandel and Barnes, “Accuracy”; Mandel and Barnes, "Geopolitical Forecasting." 
${ }^{62}$ Gary H. McClelland, "Use of Signal Detection Theory as a Tool for Enhancing Performance and Evaluating Tradecraft in Intelligence Analysis," in Intelligence Analysis: Behavioral and Social Scientific Foundations, ed. Baruch Fischhoff and Cherie Chauvin (Washington, DC: The National Academies Press, 2011), pp.83-99; Mellers et al., "Psychological Strategies"; David R. Mandel, "Accuracy of Intelligence Forecasts from the Intelligence Consumer's Perspective," Policy Insights from the Behavioral and Brain Sciences, Vol.2, No.1 (2015): pp.111-20; Chang and Tetlock, "Rethinking the Training"; Welton Chang, Elissabeth Berdini, David R. Mandel, and Philip E. Tetlock, "Restructuring Structured Analytic Techniques in Intelligence," Intelligence and National Security, Vol.33, No.3 (2018): pp.337-56; see also discussion of intelligence "batting averages" in Richard K. Betts, Enemies of Intelligence: Knowledge and Power in American National Security (New York: Columbia University Press, 2007).

${ }^{63}$ For empirical evidence, see Mandel, Karvetski, and Dhami, "Boosting Intelligence"; Martha

Whitesmith, "The Efficacy of ACH in Mitigating Serial Position Effects and Confirmation Bias in an Intelligence Analysis Scenario," Intelligence and National Security, Vol.34, No.2 (2019): pp.225-42; Mandeep K. Dhami, Ian K. Belton, and David R. Mandel, “The 'Analysis of Competing Hypotheses' in Intelligence Analysis," Applied Cognitive Psychology, Vol.33, No.6 (2019): pp.1080-90; Karvetski, Mandel, and Irwin, "Improving Probability"; for analysis, see Chang et al., "Restructuring"; Mandel, "Occasional Maverick."

${ }^{64}$ Amy B. Zegart, "September 11 and the Adaptation Failure of U.S. Intelligence Agencies," International Security, Vol.29, No.4 (2005): pp.78-111.

${ }^{65}$ Ibid.

${ }^{66}$ John A. Gentry, “The Intelligence of Fear," Intelligence and National Security, Vol.32, No.1 (2017): pp.9-25.

${ }^{67}$ Loch K. Johnson, “A Shock Theory of Congressional Accountability for Intelligence," Handbook of Intelligence Studies, ed. Loch K. Johnson (New York: Routledge, 2006), pp.343-60; Deborah G. Barger, Toward a Revolution in Intelligence Affairs (Santa Monica, CA: RAND National Security Research Division, 2005); Michael Warner and J. Kenneth McDonald, US Intelligence Community Reform Studies Since 1947 (Washington, DC: Center for the Study of Intelligence, 2005).

${ }^{68}$ Warner and McDonald, US Intelligence; Marchio, "Weatherman."

${ }^{69}$ Barnes, "Making Intelligence."

${ }^{70}$ Ibid.; Irwin and David R. Mandel, "Variants."

${ }^{71}$ Marchio, "Weatherman." 
${ }^{72}$ Zegart, "September 11."

${ }^{73}$ Warner and McDonald, US Intelligence.

${ }^{74}$ Ibid.

${ }^{75}$ Ibid.; Michael A. Turner, "Intelligence Reform and the Politics of Entrenchment," International Journal of Intelligence and CounterIntelligence, Vol.18, No.3 (2005): pp.383-97; Robert D. Vickers, “The Intelligence Reform Quandary,” International Journal of Intelligence and CounterIntelligence, Vol.19, No.2 (2006): pp.356-64; Thomas H. Hammond, "Why is the Intelligence Community so Difficult to Redesign? Smart Practices, Conflicting Goals, and the Creation of Purpose Based Organizations," Governance, Vol.20, No.3 (2007): pp.401-22; Richard J. Harknett and James A. Stever, "The Struggle to Reform Intelligence After 9/11," Public Administration Review, Vol.71, No.5 (2011): pp.700-06.

${ }^{76}$ Tetlock, "Social Functionalist."

${ }^{77}$ Piercey, "Motivated Reasoning”; Gentry, "Intelligence of Fear”; Friedman, War and Chance, pp.138-50.

${ }^{78}$ John A. Gentry, “Assessing Intelligence Performance," in The Oxford Handbook of National Security Intelligence, ed. Loch K. Johnson (New York: Oxford University Press, 2010), pp.87-103; Gentry, "Intelligence of Fear”; Friedman, War and Chance, pp.138-50.

${ }^{79}$ Friedman, War and Chance, pp.107-08; 142-44.

${ }^{80}$ Ibid., pp.19-20; 142-44.

${ }^{81}$ Jack Davis, "How Bad Things Happen to Good Analysts," in Analyzing Intelligence: Origins, Obstacles, and Innovations, $2^{\text {nd }}$ ed., ed. Roger Z. George and James (Washington, DC: Georgetown University Press, 2008), pp.157-70; Robert Jervis, "Why Intelligence and Policymakers Clash,” Political Science Quarterly, Vol.125, No.2 (2010): pp.185-204; Joshua Rovner, Fixing the Facts: National Security and the Politics of Intelligence (Ithaca, NY: Cornell University Press, 2011), pp.11-13; Patrick S. Roberts and Robert P. Saldin, "Why Presidents Sometimes Do Not Use Intelligence Information," Political Science Quarterly, Vol.131, No.4 (2016): pp.779-802.

${ }^{82}$ Philip E. Tetlock and Dan Gardner, Superforecasting: The Art and Science of Prediction (New York: Crown Publishers/Random House, 2015), pp.57-59; Adrien E. Raftery, "Use and Communication of Probabilistic Forecasts," Statistical Analysis and Data Mining, Vol.9, No.6 (2016): pp.397-410; Rex Brynen, "Here (Very Likely) Be Dragons: The Challenges of Strategic Forecasting," in Strategic Analysis in Support of International Policy Making: Case Studies in Achieving Analytical Relevance, ed. Thomas Juneau (Lanham, MD: Rowman \& Littlefield, 2017), pp.57-76; Gentry, "Intelligence of Fear." 
${ }^{83}$ Ibid.

${ }^{84}$ Mandel and Barnes, “Accuracy”; Mandel and Barnes, "Geopolitical Forecasting.”

${ }^{85}$ Mark M. Lowenthal, "Tribal Tongues: Intelligence Consumers, Intelligence Producers,” The Washington Quarterly, Vol.15, No.1 (1992): pp.157-68; Philip E. Tetlock and Barbara A. Mellers. "Intelligent Management of Intelligence Agencies: Beyond Accountability PingPong," The American Psychologist, Vol.66, No.6 (2011): pp.542-54; Gentry, "Intelligence of Fear"; Stephen Marrin, "Why Strategic Intelligence Analysis has Limited Influence on American Foreign Policy," Intelligence and National Security, Vol.32, No.6 (2017): pp.725-42.

${ }^{86}$ Dieckmann, Mauro, and Slovic, "Effects."

${ }^{87}$ Sarah C. Jenkins, Adam J. L. Harris, and R. Murray Lark, "Maintaining Credibility When Communicating Uncertainty: The Role of Communication Format," in Proceedings of the 39th Annual Conference of the Cognitive Science Society, eds. Glenn Gunzelmann, Andrew Howes, Thora Tenbrink, and Eddy J. Davelaar (London: Cognitive Science Society, 2017) pp.582-87; Sarah C. Jenkins, Adam J. L. Harris, and R. Murray Lark, "When Unlikely Outcomes Occur: The Role of Communication Format in Maintaining Communicator Credibility," Journal of Risk Research: Cambridge 'Risk and Uncertainty' Conference Special Issue, Vol.22, No.5 (2019): pp.537-54; Friedman, War and Chance, pp.152-59; Collins and Mandel, "Cultivating Credibility"; Sarah C. Jenkins and Adam J. L. Harris, "Maintaining Credibility when Communicating Uncertainty: The Role of Directionality," Thinking \& Reasoning (2020): pp.1-27.

${ }^{88}$ Gentry, "Intelligence of Fear."

${ }^{89}$ Ibid.; William Nolte, "US Intelligence and its Future: Aligning with a New and Complex Environment," Intelligence and National Security, Vol.34, No.4 (2019): pp.615-18.

${ }^{90}$ Zegart, "September 11."

${ }^{91}$ Robert Cardillo, “A Cultural Evolution," Studies in Intelligence, Vol.54, No.2 (2010): pp.4349; Tetlock and Mellers. "Intelligent Management”; Gentry, "The Intelligence of Fear."

92 John A. Gentry, "Has the ODNI Improved U.S. Intelligence Analysis?” International Journal of Intelligence and CounterIntelligence, Vol.28, No.4 (2015): pp.637-61; Gentry, "Intelligence of Fear."

${ }^{93}$ Christopher Hood, The Blame Game: Spin, Bureaucracy, and Self-Preservation in Government (Princeton, NJ; Oxford: Princeton University Press, 2011), pp.181-85.

${ }^{94}$ Paul J. DiMaggio and Walter W. Powell, “The Iron Cage Revisited: Institutional Isomorphism and Collective Rationality in Organizational Fields," American Sociological Review, Vol.48, No.2 (1983): pp.147-60; Mandel and Tetlock, "Correcting Judgment." 
${ }^{95}$ DiMaggio and Powell, "Iron Cage"; Richard Morgan, "Oversight through Five Eyes: Institutional Convergence and the Structure of Oversight of Intelligence Activities," in Global Intelligence Oversight: Governing Security in the Twenty-First Century, eds. Zachary K. Goldman and Samuel J. Rascoff (New York: Oxford University Press), pp.3770.

${ }^{96}$ Gerd Gigerenzer, Wolfgang Gaissmaier, Elke Kurz-Milcke, Lisa M. Schwartz, and Steven Woloshin, "Helping Doctors and Patients Make Sense of Health Statistics," Psychological Science in the Public Interest, Vol.8, No.2 (2007): pp.53-96; Robert Jervis, Perception and Misperception in International Politics: New Edition (Princeton, NJ: Princeton University Press, 2017).

${ }^{97}$ Friedman, War and Chance, pp.95-120.

${ }^{98}$ Kent, "Words"; see also discussions in Charles Weiss, "Communicating Uncertainty in Intelligence and Other Professions," International Journal of Intelligence and CounterIntelligence, Vol.21, No.1 (2012): pp.57-85; David R. Mandel, "Systematic Monitoring of Forecasting Skill in Strategic Intelligence" in Assessment and Communication of Uncertainty in Intelligence to Support Decision Making: Final Report of Research Task Group SAS-114, ed. David R. Mandel (Brussels: NATO Science and Technology Organization, 2020), pp.177-92.

99 James B. Steinberg, “The Policymaker's Perspective: Transparency and Partnership," in Analyzing Intelligence: Origins, Obstacles, and Innovations, $2^{\text {nd }}$ ed., eds. Roger Z. George and James B. Bruce (Washington, DC: Georgetown University Press, 2008), p.85.

${ }^{100}$ For instance, Mark Lowenthal's popular intelligence studies textbook, Intelligence: From Secrets to Policy, warns that numeric probabilities "may be more satisfying than words, but $[\ldots]$ run the risk of conveying to the policy client a degree of precision that does not exist.” (p.192); for examples in medicine, see Dennis G. Fryback, "Decision Maker, Quantify Thyself!” Medical Decision Making, Vol.5, No.1 (1985): pp.51-60; Danielle R. M. Timmermans and Philip A. Mileman, "Lost for Words: Using Verbal Terms to Express Probabilities in Oral Radiology," Dento Maxillo Facial Radiology, Vol.22, No.4 (1993): pp.171-72.

${ }^{101}$ Kent, "Words"; Mandel and Barnes, "Accuracy."

${ }^{102}$ Friedman, War and Chance, p.67.

${ }^{103}$ Thomas S. Wallsten and David V. Budescu, "Processing Linguistic Probabilities: General Principles and Empirical Evidence," Psychology of Learning and Motivation, Vol.32 (1995): pp.275-318.

${ }^{104}$ Weiss, "Communicating Uncertainty"; Friedman, War and Chance, pp.108-09. 
${ }^{105}$ Friedman and Zeckhauser, "Assessing Uncertainty."

${ }^{106}$ Brun and Teigen, "Verbal Probabilities"; Ido Erev and Brent L. Cohen, "Verbal Versus Numerical Probabilities: Efficiency, Biases, and the Preference Paradox," Organizational Behavior and Human Decision Processes, Vol.45, No.1 (1990): pp.1-18; Thomas S. Wallsten, David V. Budescu, Rami Zwick, and Steven M. Kemp, "Preferences and Reasons for Communicating Probabilistic Information in Verbal or Numerical Terms," Bulletin of the Psychonomic Society, Vol.31, No.2 (1993): pp.135-38.

${ }^{107}$ Marie Juanchich and Miroslav Sirota, "Most Family Physicians Report Communicating the Risks of Adverse Drug Reactions in Words (vs. Numbers)," Applied Cognitive Psychology, Vol.34, No.2 (2019): pp.526-34; Emily D. Lenhardt, Rachael N. Cross, Makenzie J. Krocak, Joseph T. Ripberger, Sean R. Ernst, Carol L. Silva, and Hank C. Jenkins-Smith, "How Likely is That Chance of Thunderstorms? A Study of How National Weather Service Forecast Offices Use Words of Estimative Probability and What They Mean to the Public," Journal of Operational Meteorology, Vol.8, No.5 (2020): pp.6478.Michael J. Olson and David V. Budescu, "Patterns of Preference for Numerical and Verbal Probabilities," Journal of Behavioral Decision Making, Vol.10, No.2 (1998): pp.117-31.

${ }^{108}$ Dieckmann, Mauro, and Slovic, "Effects"; Jeffrey A. Friedman, Jennifer S. Lerner, and Richard Zeckhauser, "Behavioral Consequences of Probabilistic Precision: Experimental Evidence from National Security Professionals," International Organization, Vol.71, No.4 (2017): pp.803-26.

${ }^{109}$ Friedman, Lerner, and Zeckhauser, "Behavioral Consequences."

${ }^{110}$ Marcos Degaut, "Spies and Policymakers: Intelligence in the Information Age," Intelligence and National Security, Vol.31, No.4 (2015): pp.509-31. 